\title{
Phytochemical screening, phenolic acid profiling and antioxidant activity analysis of peels from selected mango (Mangifera spp.) genotypes in the Philippines
}

\author{
1,2,*'Ocampo, E.T.M., ${ }^{1,3}$ Libron, J.A.M.A., ${ }^{1}$ Guevarra, M.L.D. and ${ }^{1}$ Mateo, J.M.C. \\ ${ }^{1}$ Institute of Plant Breeding, College of Agriculture and Food Science, University of the Philippines Los \\ Baños, College, Los Baños, Laguna, Philippines 4031 \\ ${ }^{2}$ Institute of Crop Science, College of Agriculture and Food Science, University of the Philippines Los \\ Baños, College, Los Baños, Laguna, Philippines 4031 \\ ${ }^{3}$ Institute of Chemistry, College of Arts and Sciences, University of the Philippines Los Baños, College, Los \\ Baños, Laguna, Philippines 4031
}

\begin{abstract}
Article history:
Received: 15 January 2020

Received in revised form: 3

March 2020

Accepted: 6 March 2020

Available Online: 30 March 2020
\end{abstract}

Keywords:

Mango peels,

Phytochemicals,

Antioxidant activity,

HPLC,

Mangifera indica,

Mango

DOI:

https://doi.org/10.26656/fr.2017.4(4).025

\begin{abstract}
Peels of thirteen (13) ripe mango genotypes were analyzed for total phenolic, total flavonoid, vitamin C, vitamin A contents, and antioxidant activity. Statistical analysis showed that the mango genotypes were significantly different in all the chemical assays performed. The total phenolic content of the genotypes ranged from 3.44-14.59\% GAE while total flavonoid content ranged from $0.32-2.16 \% \mathrm{CE}$. The vitamin A and vitamin $\mathrm{C}$ contents of mango peels ranged from $24.66-92.01 \mathrm{IU} / \mathrm{g}$ and $4.55-6.40 \mathrm{mg} / \mathrm{g}$, respectively. The DPPH radical scavenging activity ranged from $88.11-92.47 \%$. Correlation analysis also showed that DPPH radical scavenging activity has high positive correlation with total phenolic content $(\mathrm{r}=0.69)$, total flavonoid $(\mathrm{r}=0.77)$ content, and vitamin $\mathrm{C}(\mathrm{r}=0.57)$. Using standards, the presence of gallic, vanillic, syringic, and ferulic acids were confirmed in Carabao mango peel by comparison of retention times using High Performance Liquid Chromatography (HPLC). The quantity of these phenolic acids was also calculated with gallic acid and ferulic acid having the highest and lowest concentrations in the peels of all the studied genotypes, respectively. The observation and data collected from this study showed that there was chemical variation in the peels of different mango genotypes that can be a basis for future breeding work. Furthermore, mango peel was can be a good source of phenolic compounds, vitamins and antioxidants which can be utilized as a functional food, and for nutraceutical, pharmaceutical and cosmeceutical purposes.
\end{abstract}

\section{Introduction}

Diets rich in fruits and vegetables are important because of their potential roles in reducing the risks of cardiovascular diseases, cancer, and other chronic diseases. Oxidative damage in living organisms is caused by the excessive production of free radicals which are precursors to the development of degenerative diseases. Thus, substances with high antioxidant activities that delay or prevent oxidation of substrates are of great interest (Ajila et al., 2007).

Mango (Mangifera indica L.) is one of the most important tropical fruits marketed in the world. About 46.51 million tons of mangoes were produced around the world in 2016 (Litz, 2009; Statista, 2018) and the volume of traded mangoes increased significantly since the 1990s. Mango is considered as a good source of dietary antioxidants such as phenolic compounds, ascorbic acid, and carotenoids (Scieber et al., 2000).

In the Philippines, mango ranks third in economic importance next to banana and pineapple. Worldwide, the Philippines ranked $7^{\text {th }}$ in exports of fresh and dried mangoes in 2015 but fresh mango exports have declined in the recent years because of failed compliance with the strict sanitary and phytosanitary treatments of international markets (Stark et al., 2017). Mango is processed into dried chips, jams, puree, fruit bars, concentrates, juice, nectar, and jelly powders aside from being consumed as fresh cuts generating a high volume of by-products (Bernardini et al., 2005). The Philippines 
processed mango exports scaled up to US\$ 91 million in 2014. The largest portion of export is accounted to dried mango (77\%), followed by juice (9\%), airtight ( $8 \%$ ), and lastly the puree (7\%) (Stark et al., 2017).

In mango, the peel comprises $35 \%$ of the total fruit weight, which go to waste after processing (Schieber et al., 2003). Annually, around 24.7 to 33 million $\mathrm{kg}$ of mango peels is unused from the processors alone which may still be consumed for other commercial purposes (Gragasin et al., 2014). Several studies observed that secondary metabolites in mango are concentrated in peel, seed, kernel, and bark resulting in the high amounts of phytochemicals and antioxidant capacity of these fruit/ plant parts (Fadzelly et al., 2009).

Phytochemicals are secondary metabolites synthesized by plants in order to aid in defence against competitors, herbivores, and microorganisms (Molyneux et al., 2007). These compounds also help in controlling pollination, fertilization, influence rhizosphere environment, and delay seed germination until the appropriate time to sprout (Molyneux et al., 2007). The different biological functions of these compounds may be attributed to their antioxidant properties. Thus, there has been increasing interest to study mango phytochemicals from fruit peels, leaves, seeds, and stem bark in order to utilize these by-products from mango processing and make them natural ingredients for nutritive food production, pharmaceutical, cosmeceutical and nutraceutical purposes (Schieber et al., 2001).

A variety of phytochemicals such as polyphenols and carotenoids are present in mango. Major polyphenols found in its different parts include gallic acid, quercetin, mangiferin, rhamnetin, catechin, ellagic acid, anthocyanin, benzoic acid, protocatechuic acid, propyl and methyl gallate, and kaempferol. The amount of total phenols in peel is higher than in flesh at all stages of fruit development (Masibo and $\mathrm{He}, 2008$ ). On the other hand, carotenoids that are usually present in mango include lutein, a-carotene, and the main pigment $\beta$-carotene which is responsible for the yellow pigmentation of most mango varieties (Parvez, 2016).

Although different studies have observed varietal differences in different bioactive compounds in mango peel, no similar study has been performed using Philippine varieties. Thus, this study aimed to assess different Philippine mangoes for phytochemical and antioxidant compounds and identify promising mango genotypes with desirable phytochemical and antioxidant profiles.

\section{Materials and methods}

\subsection{Materials}

The genotypes used in this study were Carabao 'GES 73', Carabao 'GES 77', Carabao 'GES 84', Carabao 'GES 85', Katchamita 1, Katchamita 2, Katchamita 3, Pico 1, Red Admin 1, Red Admin 2, Apple Mango 2, Apple Mango 3 and Huani 1. Huani genotype belongs to the Mangifera odorota species while the rest are Mangifera indica. Figure 1 shows the pictures of ripe fruits of the mango genotypes used in the study. Fruits of Carabao accessions came from the National Mango Research and Development Center in Jordan, Guimaras Island. Fruits from non-Carabao genotypes were harvested from trees of the National Plant Genetic Resources Laboratory and the Fruits and Ornamental Crops Breeding Division of the Institute of Plant Breeding, College of Agriculture and Food Science, in UPLB.

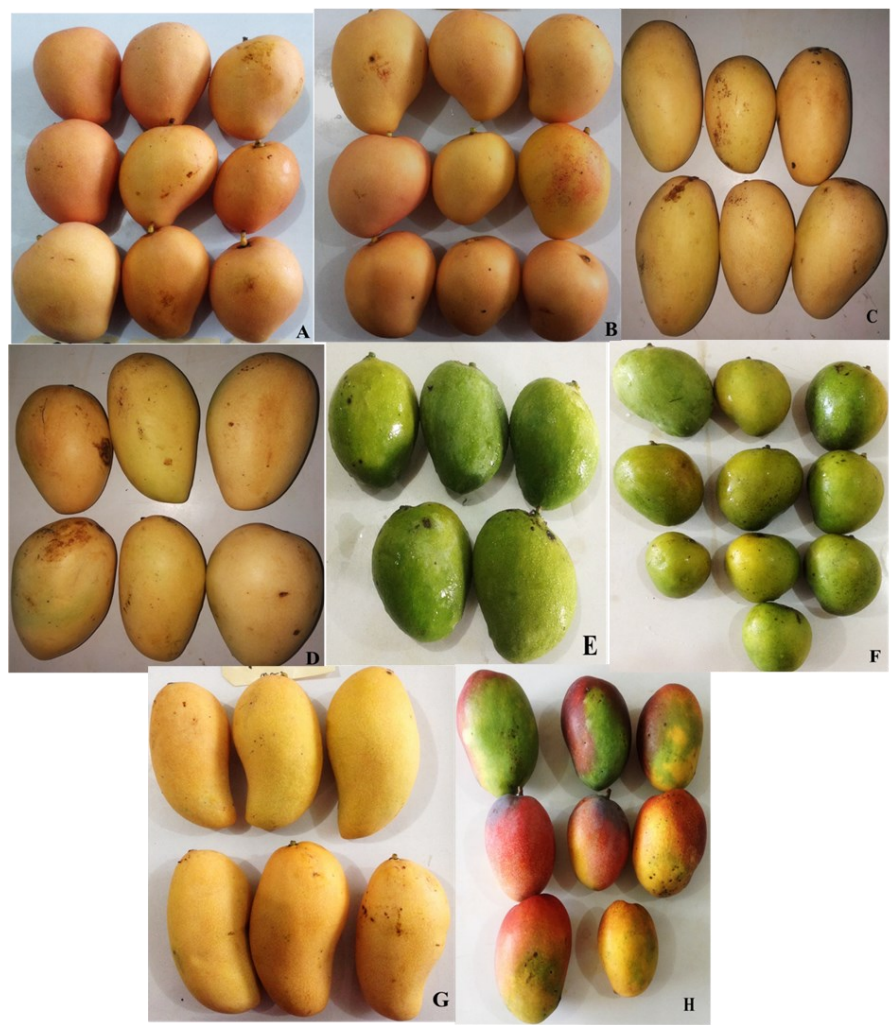

Figure 1. Mango samples: Apple mango 2 (A), Apple mango 3 (B), Carabao 'GES 84' (C), Carabao 'GES 85' (D), Katchamita 1 (E), Katchamita 2 (F), Pico 1 (G), Red Admin (H).

All reagents used were analytical grade. For all spectrophotometric chemical assays, Shimadzu ${ }^{\circledR}$ UVmini 1480 (Japan) was used.

\subsection{Sample preparation}

The peels were separated from the pulp of full yellow ripe mangoes using a stainless steel knife. After separation, the peels were cut into smaller pieces and oven-dried at $45^{\circ} \mathrm{C}$ for $48 \mathrm{hrs}$. The dried peels were pulverized using a grinder. Pulverized dried samples 
were used for different analyses.

\subsection{Phytochemical contents}

A total of $50 \mathrm{mg}$ of ground samples were added to 10 $\mathrm{mL} 50 \%$ methanol (1:1 vol/vol absolute methanol: distilled water). The mixture was vortexed at medium speed for $3 \mathrm{mins}$, then centrifuged at $3000 \mathrm{rpm}$ for 5 mins. The supernatant was collected and used for determination of total phenolic, total flavonoid content, and 2, 2-diphenyl-1-picrylhydrazyl (DPPH) radical scavenging activity assays.

\subsection{Total phenolic content}

Total phenolic content was determined colorimetrically using Folin-Ciocalteau assay with gallic acid as standard (Velioglu et al., 1998). About $2.9 \mathrm{~mL}$ distilled water was added to $100 \mu \mathrm{L}$ methanol extract. Afterwards, $1 \mathrm{~mL}$ of $0.2 \mathrm{M}$ sodium carbonate and 0.2 $\mathrm{mL}$ of $50 \%$ Folin-Ciocalteu reagent were added to the solution. The solution was mixed thoroughly using a vortex mixer and placed in a boiling water bath for 15 mins. After cooling to room temperature, absorbance was measured at $710 \mathrm{~nm}$. Total phenolic content was expressed as percent gallic acid equivalents (GAE).

\subsection{Total flavonoid content}

The total flavonoid concentration was measured using a colorimetric assay using catechin as standard (Zhishen et al., 1999). In a test tube, $0.50 \mathrm{~mL}$ methanolic extract was mixed with $2.0 \mathrm{~mL}$ distilled water and 0.3 $\mathrm{mL} 5 \%(\mathrm{w} / \mathrm{v}) \mathrm{NaNO}_{2}$. After standing the solution for 5 minutes, $0.3 \mathrm{~mL}$ of $10 \% \mathrm{AlCl}_{3}$ was mixed in thoroughly and allowed to stand for $1 \mathrm{~min}$. Lastly, $1.0 \mathrm{~mL} 1.0 \mathrm{M}$ $\mathrm{NaOH}$ was added to the solution and upon the development of pink color, absorbance was read at 510 $\mathrm{nm}$. The total flavonoid contents of the samples were expressed in percent catechin equivalents (CE).

\subsection{DPPH radical scavenging activity (antioxidant activity)}

Antioxidant activity was evaluated using the 2,2diphenyl-1-picrylhydrazyl (DPPH) assay (BrandWilliams et al., 1995). DPPH (4 mg) was dissolved in $100 \mathrm{~mL}$ of absolute methanol for a final concentration of $10^{-4} \mathrm{M}$ DPPH. An aliquot $(2.9 \mathrm{~mL})$ of DPPH solution was placed in test tubes and mixed with $25 \mu \mathrm{L}$ of samples and $75 \mu \mathrm{L}$ of $\mathrm{H}_{2} \mathrm{O}$. The solution was mixed well and incubated in the dark at $30^{\circ} \mathrm{C}$ for 30 mins followed by reading absorbance at $517 \mathrm{~nm}$.

\subsection{Vitamin content}

\subsubsection{Ascorbic acid/vitamin C content}

The ascorbic acid content was determined using a modified colorimetric assay (Jagota and Dani 1982). Fifty milligrams of dried ground mango peel were extracted twice with $5.0 \mathrm{~mL} 10 \%$ trichloroacetic acid and mixed using a vortex for 5 mins. The resulting mixture was allowed to stand for 5 mins in an ice water bath and then centrifuged at $3000 \mathrm{rpm}$ for 5 mins. Approximately $0.50 \mathrm{~mL} 10 \%$ Folin Ciocalteu reagent was added to the $1.0 \mathrm{~mL}$ aliquot trichloroacetic acid extract and the mixture was allowed to stand for 10 mins. The absorbance of the resulting blue-colored mixture was read at $760 \mathrm{~nm}$. A standard curve was prepared using ascorbic acid and vitamin $\mathrm{C}$ content was calculated using the interpolation method.

\subsection{2 $\beta$-carotene/vitamin A content}

The beta-carotene content was determined using a colorimetric assay developed by Biswas et al. (2011). Dried and ground mango peel of $1 \mathrm{~g}$ was extracted twice using $5.0 \mathrm{~mL}$ chilled acetone and was allowed to stand in an ice bath for 15 mins with occasional shaking. The supernatants were pooled and filtered using Whatman filter paper No. 42. The absorbance of the extract was read at $449 \mathrm{~nm}$. The $\beta$-carotene content of the mango peel was calculated from the $\beta$-carotene standard curve using the interpolation method. Vitamin A was determined using a conversion factor suggested by the US Department of Agriculture (USDA). Vitamin A: 1 International Unit $(\mathrm{IU})=0.60 \mu \mathrm{g}$ of beta-carotene.

2.8 Phytochemical profiling of phenolic compounds of mango (Mangifera indica L.) using reversed phase-high performance liquid chromatography (RP-HPLC)

\subsubsection{Preparation of extracts}

About $50 \mathrm{mg}$ of dried peel powder was extracted twice using 80:20 methanol: water acidified with $1 \%$ acetic acid. The mixture was centrifuged at $3000 \mathrm{rpm}$ for 5 mins and decanted to a vial. Extracts were transferred to a specialized vial using a syringe filter and directly injected and analyzed in High Performance Liquid Chromatography (HPLC) system. Phenolic compounds that were used as standards were vanillic, ferulic, gallic, coumaric, and syringic acids.

\subsubsection{High-performance liquid chromatography (HPLC)}

Reversed-Phase High Performance Liquid Chromatography (RP-HPLC) was performed using Waters Alliance e2695 (USA) with SunFire ${ }^{\mathrm{TM}}$ C18 (4.6 $\mathrm{mm}$ x $50 \mathrm{~mm}, 3.5 \mu \mathrm{m})$ column. The mobile phase was composed of two solvents: $0.1 \%$ trifluoroacetic acid in water (A) and $0.1 \%$ trifluoroacetic acid in acetonitrile (B). The flow rate was set to $1.0 \mathrm{~mL} / \mathrm{min}$, injection volume was $20 \mu \mathrm{L}$ and the total runtime was 80 mins. The elution gradient used was: 0-5 mins. (100-92\%A), 5 
-15 mins. (92-95 \%A), 15-35 mins. (95-85 \%A), 35-40 mins. (85-80 \%A), 40-50 mins. (80-75\%A), 50-65 mins. (75-70 \%A), 65-70 mins. (70-90\%A) and 70-80 mins. (90-100\%A). Chromatogram was monitored at 280 and $320 \mathrm{~nm}$ using Waters $2489 \mathrm{UV} / \mathrm{Vis}$ detector. Eluent peaks were identified using retention time comparison with available standards. Gallic acid was quantified using $25,50,100,150,200 \mathrm{ppm}$ standards while vanillic, syringic and ferulic acids were quantified using 5, 10, 15, 20, 25 ppm standards.

\subsection{Statistical analysis}

One-way ANOVA, Pearson correlation and Tukey's multiple range test at $95 \%$ confidence interval $(p \leq 0.05)$ were performed using Statistical Tool for Agricultural Research (STAR) version 2.0.1. The Pearson correlation coefficient (r) and p-value were used to show correlations and significance, respectively.

\section{Results and discussion}

\subsection{Phytochemical contents}

\subsubsection{Total phenolic content}

Polyphenols are the most abundant compounds in mango. Table 1 summarizes the results for the total phenolic content, total flavonoid content and antioxidant activity of the mango genotypes. The total phenolic content (TPC) of mango peel varied significantly ( $\mathrm{p}<$ 0.05 ) among accessions ranging from $3.44-14.59 \% \mathrm{GAE}$ with a mean of $8.54 \%$. The mango genotypes used showed higher TPC compared to the reported mean TPC of Barreto et al. (2008) of $2.51 \%$ for the Tommy Atkins variety. The Carabao mango genotypes registered the highest TPC (Carabao 'GES 73' with 14.59\%, Carabao 'GES 84' with $13.77 \%$ and Carabao 'GES 85' with 13.53\%) while Red Admin 1 and 2 have the lowest TPC with 4.86 and $3.45 \%$ GAE respectively. The differences in total phenolic content may be attributed to the difference in the genetic makeup of the genotypes, changes of the phenolic pattern during fruit development and degree of expression of phenolic compounds as plants' response to different biotic and abiotic stresses (Schieber et al., 2000).

\subsubsection{Total flavonoid content}

Flavonoid compounds also act as antioxidants and free radical scavengers. In plants, these compounds act as unique UV filters and serve as protection against abiotic and biotic stresses (Panche et al., 2016). The flavonoid content (TFC) of the analyzed mango peel extracts varied significantly $(\mathrm{p}<0.05)$ ranging from 0.32 - $2.16 \%$ CE with a mean of $1.03 \%$. Carabao mango genotypes registered the highest TFC with 'GES $85^{\prime}(2.16 \%)$ containing the highest amount of TFC followed by Carabao 'GES 73' (2.12\%) and Carabao 'GES 84' (1.96\%). On the other hand, Katchamita, Apple Mango and Red Admin genotypes registered low TFC with Red Admin 2 registering the lowest TFC with $0.32 \%$ followed by Katchamita 3 with $0.37 \%$. The average TFC (1.03\%) of the analyzed samples was lower compared to the reported TFC by Kim et al. (2010) using Irwin variety where the TFC of mango peel extracted was $2.12 \%$ CE. The difference in flavonoid content in plants, in general, is influenced by different factors such as cultivar, agricultural practices, growing locations, and ultraviolet radiation (Ferreyra et al., 2012).

Table 1. Phytochemical content and antioxidant activity of the peels from selected Philippine mango genotypes.

\begin{tabular}{cccc}
\hline Accession name & Total Phenols (\% GAE) & Total Flavonoids (\% CE) & Antioxidant Activity (\% RSA) \\
\hline Apple Mango 2 & $5.04 \pm 0.26^{\mathrm{fg}}$ & $0.53 \pm 0.06^{\mathrm{fgh}}$ & $89.86 \pm 0.20^{\mathrm{fg}}$ \\
Apple Mango 3 & $5.64 \pm 0.68^{\text {ef }}$ & $0.50 \pm 0.03^{\text {fghi }}$ & $88.11 \pm 0.64^{\mathrm{h}}$ \\
Carabao 'GES 73' & $14.59 \pm 0.19^{\mathrm{a}}$ & $2.12 \pm 0.05^{\mathrm{ab}}$ & $91.62 \pm 0.06^{\mathrm{cd}}$ \\
Carabao 'GES 77' & $11.50 \pm 0.30^{\mathrm{c}}$ & $1.61 \pm 0.03^{\mathrm{c}}$ & $91.69 \pm 0.06^{\mathrm{bcd}}$ \\
Carabao 'GES 84' & $13.77 \pm 0.38^{\mathrm{ab}}$ & $1.96 \pm 0.03^{\mathrm{b}}$ & $92.47 \pm 0.06^{\mathrm{a}}$ \\
Carabao 'GES 85' & $13.14 \pm 0.79^{\mathrm{abc}}$ & $2.16 \pm 0.05^{\mathrm{a}}$ & $92.36 \pm 0.06^{\mathrm{ab}}$ \\
Huani 1 & $12.64 \pm 0.39^{\mathrm{bc}}$ & $1.28 \pm 0.006^{\mathrm{d}}$ & $91.52 \pm 0.06^{\mathrm{cd}}$ \\
Katchamita 1 & $5.86 \pm 0.17^{\mathrm{ef}}$ & $0.57 \pm 0.02^{\mathrm{fg}}$ & $90.56 \pm 0.11^{\mathrm{ef}}$ \\
Katchamita 2 & $7.13 \pm 0.83^{\mathrm{de}}$ & $0.67 \pm 0.08^{\mathrm{f}}$ & $88.69 \pm 0.37^{\mathrm{h}}$ \\
Katchamita 3 & $5.03 \pm 0.83^{\mathrm{fg}}$ & $0.37 \pm 0.02^{\mathrm{hi}}$ & $89.45 \pm 0.37^{\mathrm{g}}$ \\
Pico 1 & $8.41 \pm 0.34^{\mathrm{d}}$ & $0.86 \pm 0.17^{\mathrm{e}}$ & $91.98 \pm 0.11^{\mathrm{abc}}$ \\
Red Admin 1 & $4.86 \pm 0.64^{\mathrm{fg}}$ & $0.44 \pm 0.05^{\text {ghi }}$ & $91.06 \pm 0.10^{\mathrm{de}}$ \\
Red Admin 2 & $3.45 \pm 0.82^{\mathrm{g}}$ & $0.32 \pm 0.04^{\mathrm{i}}$ & $90.34 \pm 0.15^{\text {ef }}$
\end{tabular}

*Data are means \pm standard deviation of triplicate analysis based on the dry weight of the samples;

* Mean values followed by different letters in the same column differ significantly $(\mathrm{p} \leq 0.05)$;

*Total phenol content is expressed as percent gallic acid equivalent;

*Total flavonoid content is expressed as percent catechin equivalent;

*Antioxidant activity expressed as \%DPPH radical scavenging activity 
3.1.3 DPPH radical scavenging activity (antioxidant activity)

In this study, the antioxidant activity of mango peel was determined using the DPPH assay. The degree of discoloration of the DPPH solution determined the scavenging potential of the extract. Mango genotypes were shown to differ significantly in DPPH radical scavenging activity $(100 \mathrm{ppm}(\mathrm{w} / \mathrm{v})$ peel extract) ranging from $88.11-92.47 \%(\mathrm{p}<0.05)$ and an average of 90.75\%. Carabao 'GES 84' (92.47\%), Carabao 'GES $85^{\prime}(92.36 \%)$, and Pico 1 (91.98\%) were the three genotypes with the highest antioxidant activity while Apple Mango 3 has the lowest radical scavenging activity (RSA). Butylated hydroxyanisole (BHA), an established antioxidant, was used to compare the antioxidant capacity of mango peels. One hundred (100) $\mathrm{ppm}(\mathrm{w} / \mathrm{v})$ of BHA registered $88.38 \% \mathrm{RSA}$ is lower in antioxidant capacity compared with the studied extracts except with Apple Mango 3. This result showed that mango peel extract can act as a good antioxidant and is at par or even better than commercially available antioxidants like BHA.

Ajila et al. (2007) also showed the same results and reported higher radical scavenging activity of ripe Raspuri mango peel extracts (1.83 ug GAE) compared to BHA (3.45 ug GAE). Mango peel has been shown to have higher radical scavenging activity $(53.3 \%)$ than seed $(24.2 \%)$ using Uba variety which may be credited to the elevated concentration of flavonol and xanthone glycosides in peel (Ribeiro et al., 2008).

The observed high antioxidant activity across the mango peel samples may aid in the utilization of peels for functional food, nutraceutical, pharmaceutical and even cosmeceutical purposes. Genetic variability has the utmost influence in the production of plant secondary metabolites which are correlated to the plant's antioxidant activity. Moreover, right after harvest, metabolism of phytochemicals begins which involves complex biochemical reactions during storage and transportation which may increase or decrease the phytochemicals of plants or plant parts (Li et al., 2012).

\subsection{Vitamin contents}

\subsection{1 $\beta$-carotene/vitamin A content}

$\beta$-carotene is a member of the carotenoid family that participates in general antioxidant functions and as an accessory pigment in light absorption and energy dissipation during photosynthesis (Kopsell and Kopsell, 2010). Ripening increases the carotenoid content because of the development of the yellow color in the peel (Varakumar et al., 2011). The vitamin A content in the peels of selected mango genotypes varied significantly ( $p$
$<0.05$ ) ranging from $24.66-92.01$ IU with a mean of 44.99 IU (Table 2). The highest amount of $\beta$-carotene/ Vitamin A was observed in Red Admin genotypes with Red Admin 2 having 92.01 IU and Red Admin 1 with 59.08 IU while Apple Mango 2 had the lowest Vitamin A content with 24.66 IU.

Table 2. Vitamin A and C contents of the peels from selected Philippine mango genotypes.

\begin{tabular}{lcc}
\hline Accession name & Vitamin A (IU) & Vitamin C (mg/g) \\
\hline Apple Mango 2 & $24.66 \pm 0.46^{\mathrm{h}}$ & $4.77 \pm 0.05^{\mathrm{e}}$ \\
Apple Mango 3 & $32.45 \pm 1.19^{\mathrm{fg}}$ & $4.84 \pm 0.04^{\mathrm{e}}$ \\
Carabao 'GES 73' & $32.67 \pm 0.55^{\mathrm{fg}}$ & $6.40 \pm 0.08^{\mathrm{a}}$ \\
Carabao 'GES 77' $^{\mathrm{g}}$ & $29.04 \pm 0.55^{\mathrm{gh}}$ & $5.81 \pm 0.08^{\mathrm{c}}$ \\
Carabao 'GES 84' $^{\mathrm{c}}$ & $49.70 \pm 2.48^{\mathrm{cd}}$ & $5.94 \pm 0.09^{\mathrm{c}}$ \\
Carabao 'GES 85' & $28.22 \pm 0.95^{\mathrm{gh}}$ & $6.21 \pm 0.04^{\mathrm{ab}}$ \\
Huani 1 & $40.65 \pm 2.17^{\mathrm{e}}$ & $6.30 \pm 0.10^{\mathrm{ab}}$ \\
Katchamita 1 & $55.56 \pm 2.99^{\mathrm{bc}}$ & $5.75 \pm 0.03^{\mathrm{c}}$ \\
Katchamita 2 & $57.67 \pm 2.03^{\mathrm{b}}$ & $5.86 \pm 0.02^{\mathrm{c}}$ \\
Katchamita 3 & $38.16 \pm 5.08^{\mathrm{ef}}$ & $5.06 \pm 0.02^{\mathrm{d}}$ \\
Pico 1 & $44.95 \pm 1.79^{\mathrm{de}}$ & $6.14 \pm 0.12^{\mathrm{b}}$ \\
Red Admin 1 & $59.08 \pm 3.52^{\mathrm{b}}$ & $4.55 \pm 0.05^{\mathrm{f}}$ \\
Red Admin 2 & $92.01 \pm 2.18^{\mathrm{a}}$ & $4.66 \pm 0.03^{\text {ef }}$ \\
\hline
\end{tabular}

*Data are means \pm standard deviation of triplicate analysis based on the dry weight of the samples;

*Vitamin A is expressed as IU/g; and

*Vitamin C is expressed as $\mathrm{mg} / \mathrm{g}$.

\subsubsection{Ascorbic acid/vitamin C content}

Ascorbic acid, also known as vitamin C, plays a part in numerous cell function and also acts as an antioxidant. Since humans lack the ability to produce ascorbic acid, it must be obtained from dietary sources and be taken regularly since it cannot be stored in the body. It was observed that the vitamin $\mathrm{C}$ content of mango peel varied significantly $(\mathrm{p}<0.05)$ among genotypes ranging from $4.55-6.40 \mathrm{mg} / \mathrm{g}$ ascorbic acid equivalents based on statistical analysis (Table 2). The average vitamin $\mathrm{C}$ content of the genotypes was $5.56 \mathrm{mg} / \mathrm{g}$. Carabao 'GES73' has the highest vitamin C content while Red Admin 2 contained the least vitamin $\mathrm{C}$.

Vitamin C content may decrease, increase, or remain constant in the course of fruit ripening. Ortega et al. (2013) observed that the ascorbic acid content of Ataulfo mango variety increased during ripening in storage and reduced during senescence. The increase in vitamin $\mathrm{C}$ content during ripening of mango fruit may be linked to the increased activation of the biosynthesis of ascorbic acid driven by the breakdown of starch into simple sugars such as glucose. Moreover, the increase in vitamin $\mathrm{C}$ content during ripening may also be attributed to the increased lipid peroxidation as the fruit ripens (Adetuyi et al., 2016). 
3.3 Correlation analysis among the different antioxidant measurements

Correlation analysis showed that DPPH radical scavenging activity has high positive correlation with total phenolic content $(\mathrm{r}=0.69)$, total flavonoid $(\mathrm{r}=$ $0.77)$ content, and vitamin $\mathrm{C}(\mathrm{r}=0.57)(\mathrm{p}<0.05)$ (Table 3). However, there was no significant relationship between vitamin A content $(r=-0.096)$ with DPPH radical scavenging activity. These correlations clearly show that the antioxidant capacity of mango peels is primarily dictated by phenolics, flavonoids and vitamin C content of the peels. Likewise, Ma et al. (2007) also observed a high positive linear correlation between the polyphenol $(\mathrm{r}=0.98)$ and flavonoids content $(\mathrm{r}=0.91)$ with antioxidant capacity.

Table 3. Linear correlation coefficients between antioxidant activity and antioxidant variables.

\begin{tabular}{|c|c|c|c|c|c|}
\hline & & TFC & RSA & Vit. C & Vit. A \\
\hline \multirow{2}{*}{ ТPC } & Coefficient & 0.9586 & 0.6885 & 0.838 & -0.4451 \\
\hline & $p$-value & 0 & 0 & 0 & 0.0045 \\
\hline \multirow{2}{*}{$\mathrm{TFC}$} & Coefficient & & 0.7172 & 0.7598 & -0.4374 \\
\hline & p-value & & 0 & 0 & 0.0054 \\
\hline \multirow{2}{*}{ RSA } & Coefficient & & & 0.5703 & -0.0958 \\
\hline & $p$-value & & & 0.0002 & 0.5617 \\
\hline \multirow{2}{*}{ Vit. C } & Coefficient & & & & -0.3225 \\
\hline & $p$-value & & & & 0.0452 \\
\hline
\end{tabular}

\subsection{Identification and quantification of phenolic acids in mango peel}

High Performance Liquid Chromatography (HPLC) was used to determine the phenolic acid profile of mango peels. Standards used were gallic, vanillic, syringic, ferulic, coumaric and chlorogenic acids which were previously reported to be present in mango peels. The presence of these acids was confirmed by comparing the retention time of the standards with peaks generated from the mango peel samples using the HPLC parameters previously described. Figure 2 summarizes

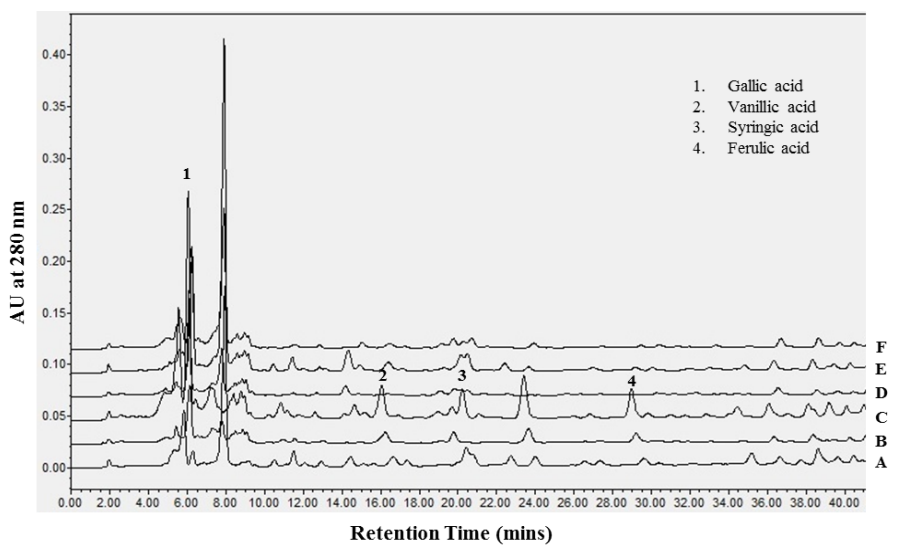

the concentration of phenolic compounds identified in mango peel using HPLC. The profile of polyphenols and its quantity in mango depends on the variety and plant part (Ma et al., 2011).

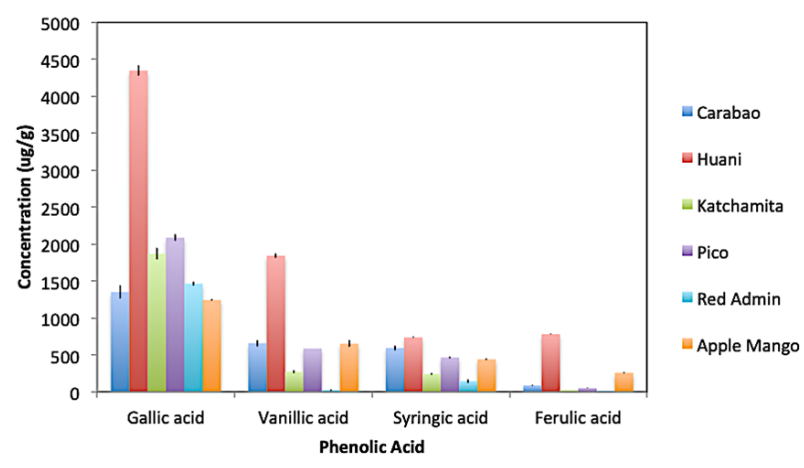

Figure 2. Concentration of phenolic acids present in the peel of selected mango genotypes determined by High Performance Liquid Chromatography.

The chromatogram (Figure 3) showed that differences exist between the phenolic profiles of each variety of mango. Gallic, vanillic, syringic, and ferulic acids (Figure 4) were positively identified in the peels of all the mango genotypes while coumaric and chlorogenic acids were not present. The presence of gallic and ferulic acids in mango peels was also reported by Sharaf et al. (2016) while Coelho et al. (2019) and Blancas-Benitez et al. (2015) confirmed the presence of syringic and vanillic acids in mango peels, respectively. Gallic acid was also reported as the common phenolic acid found in Keitt, Sensation, and Gomera 3 mango varieties (Dorta et al., 2014).

The peel of Huani genotype (Mangifera odorata) is superior in all phenolic acids quantified while the peel of Red Admin registered the lowest concentrations of phenolic acids quantified. Among the M. indica genotypes studied, Carabao mango genotype registered the highest vanillic $(660.57 \mathrm{mg} / \mathrm{g})$ and syringic acid $(593.39 \mathrm{mg} / \mathrm{g}$ ) contents while Pico and Apple Mango have the highest gallic and ferulic acids, respectively.

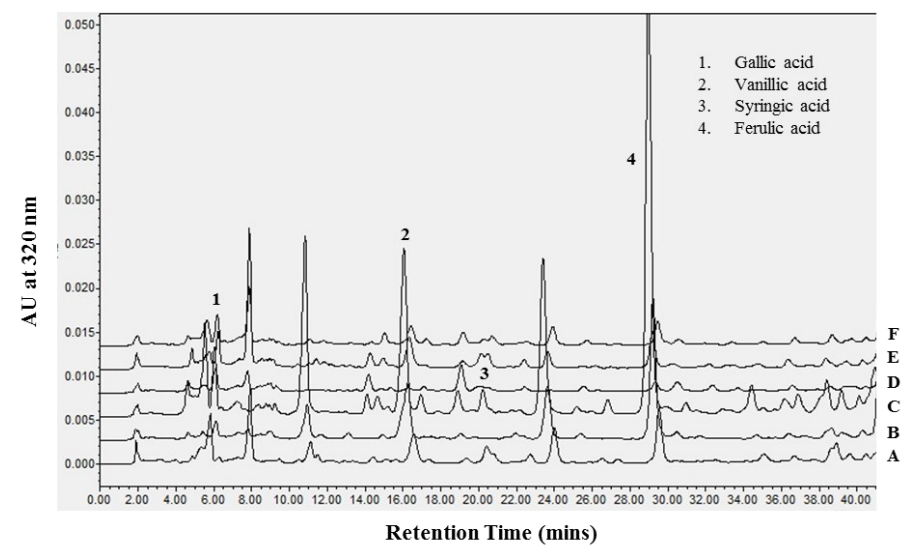

Figure 3. HPLC chromatogram 280 and $320 \mathrm{~nm}$ of mango peel extract of 'Carabao' (A), 'Apple Mango' (B), 'Huani' (C), 'Red Admin' (D), 'Pico' (E), and 'Katchamita' (F). 
The results are directly correlated with the computed total phenolic content of the peels of the genotypes studied. Carabao and Huani have the highest total phenolics while Red Admin accessions have the lowest.<smiles>COc1cc(C(=O)O)ccc1O</smiles>

B<smiles>O=C(O)c1cc(O)c(O)c(O)c1</smiles>

C<smiles>COc1cc(C(=O)O)cc(OC)c1O</smiles><smiles>COc1cc(/C=C/C(=O)O)ccc1O</smiles>

Figure 4. Structure of the identified phenolic acids in the peel of all mango genotypes studied. (A - vanillic acid, $\mathbf{B}$ - gallic acid, $\mathbf{C}$ - syringic acid, $\mathbf{D}$ - ferulic acid)

Other peaks from the chromatogram were not identified and quantified due to lack of standards available. This phenolic acid profile (chromatogram) can be used in the future as marker/fingerprint to correctly identify varieties like Carabao mango which is very famous in the Philippines because of its taste.

\section{Conclusion}

Mango peels, which are a major by-product during mango processing, possess bioactive compounds that are of great importance to nutrition and prevention of diseases. Methanolic extracts of the different mango genotypes showed a significant difference in the total phenolic, total flavonoid, vitamin A, vitamin $\mathrm{C}$ contents, and antioxidant activity. Differences in the amounts of these compounds can be mainly attributed in the genetic variation of the genotypes, post-harvest treatments growing conditions, location and biotic and abiotic stresses. Mango peels, especially the from Carabao genotypes, are a good source of phenolic and flavonoid compounds which is positively correlated with antioxidant activity and can be utilized as a functional food, nutraceutical, pharmaceutical and cosmeceutical products. Based on the results of this study, the top 3 genotypes having the most amount of bioactive compounds were Carabao 'GES 73', Carabao 'GES 84', and Carabao 'GES 85'. Lastly, the utilization of mango peels will not only be beneficial to health and nutrition, but also to the environment by the reduction of waste generation cutting significant cost to waste disposal.

\section{Acknowledgement}

The authors are grateful to the Enhanced Creative Work and Research Grant (ECWRG) awarded to ETMO
(2017-2-010) from the University of the Philippines for funding this research, the National Plant Genetic Resources Laboratory, Fruits Section and Analytical Service Laboratory of the Institute of Plant Breeding (IPB) for the use of plant materials and facilities, Ms. Marynold Purification for assisting in the HPLC analysis, Ms. Elenita Castillo and Ms. Teresita Maligalig of the Analytical Service Laboratory for assisting in sample preparation and analysis.

\section{References}

Ajila, C.M., Naidu, K.A., Bhat, S.G. and Prasada-Rao, U.J.S. (2007). Bioactive compounds and antioxidant potential of mango peel extract. Food Chemistry, 105(3), 892-988. https://doi.org/10.1016/ j.foodchem.2007.04.052

Adetuyi, F.O., Makinde, A., Adeyemi, I. and Timothy, V. (2016). Bioactive components, antioxidative properties and inhibition of $\mathrm{Fe}^{2+}$ - induced lipid peroxidation of mango peel as affected by the storage of mango fruit. International Journal of Food Studies, 5, 131-145. https://doi.org/10.7455/ ijfs/5.2.2016.a2

Barreto, J.C., Trevisan, M.T., Hull, W.E., Erben, G., De Brito, E.S., Pfundstein, B., Wurtle, G., Spiegelhalder, B. and Owen, R.W. (2008). Characterization and quantitation of polyphenolic compounds in bark, kernel, leaves, and peel of mango (Mangifera indica L.). Journal of Agricultural and Food Chemistry, 56, 5599-5610. https://doi.org/10.1021/jf800738r

Blancas-Benitez, F.J., Mercado-Mercado, G., QuirosSauceda, A.E., Montalvo-Gonzalez, E., GonzalezAguilar, G.A. and Sayago-Ayerdi, S.G. (2015). Bioaccessibility of polyphenols associated with dietary fiber and in vitro kinetics release of polyphenols in Mexican 'Ataulfo' mango (Mangifera indica L.) by-products. Food and Function, 6(3), 859-868. https://doi.org/10.1039/ C4FO00982G

Bernardini, N., Knodler, M., Schieber, A. and Carle, R. (2005). Utilization of mango peels as a source of pectin and polyphenolics. Innovative Food Science and Emerging Technologies, 6(4), 442 - 452. https:// doi.org/10.1016/j.ifset.2005.06.004

Biswas, A. K., Sahoo, J. and Chatli, M.K. (2011). A simple UV-Vis spectrophotometric method for determination of $\beta$-carotene content in raw carrot, sweet potato and supplemented chicken meat nuggets. LWT - Food Science and Technology, 44 (8), 1809-1813. https://doi.org/10.1016/ j.lwt.2011.03.017

Brand-Williams, W., Cuvelier, M.E. and Berset, C. 
(1995). Use of a free radical method to evaluate antioxidant activity. LWT - Food Science and Technology, 28(1), 25-30. https://doi.org/10.1016/ S0023-6438(95)80008-5

Coelho, E.M., de Souza, M.E.A.O., Correa, L.C., Viana, A.C., de Azevedo, L.C. and Lima, M.D.S. (2019).

Bioactive compounds and antioxidant activity of mango peel liqueurs (Mangifera indica L.) produced by different methods of maceration. Antioxidants, 8 (4), 102. https://doi.org/10.3390/antiox8040102

Dorta, E., Gonzalez, M., Lobo, M.G., Sanchez-Moreno, C. and Ancos, B.D.E. (2014). Screening of phenolic compounds in by-product extracts from mangoes (Mangifera indica L.) by HPLC-ESI-QTOF-MS and multivariate analysis for use as a food ingredient. Food Research International, 57, 51-60. https:// doi.org/10.1016/j.foodres.2014.01.012

Fadzelly, M., Bakar, A., Mohamed, M., Rahmat, A. and Fry, J. (2009). Phytochemicals and antioxidant activity of different parts of bambangan (Mangifera pajang) and tarap (Artocarpus odoratissimus). Food Chemistry, 113(2), 479-483. https://doi.org/10.1016/ j.foodchem.2008.07.081

Ferreyra, F., Lorena, M., Rius, S. and Casati, P. (2012). Flavonoids: biosynthesis, biological functions, and biotechnological applications. Frontiers in Plant Science, 2012, 222. https://doi.org/10.3389/ fpls.2012.00222

Gragasin, M.C.B., Ligisan, A.R., Torres, R.C. and Estrella, R. (2014). Utilization of mango peels as source of pectin. PHilMech Technical Bulletin, Vol. 4. Philippines: Philippine Center for Postharvest Development and Mechanization.

Jagota, S.K. and Dani, H.M. (1982). A new colorimetric technique for the estimation of vitamin $\mathrm{C}$ using Folin phenol reagent. Analytical Biochemistry, 127(1), 178 -182. https://doi.org/10.1016/0003-2697(82)90162-2

Kopsell, D.A. and Kopsell, D.E. (2010). Carotenoids in vegetables: biosynthesis, occurrence, impacts on human health, and potential for manipulation. In Watson, R.R. and Preedy, V.R. (Eds.) bioactive foods in promoting health: fruits and vegetables., $\mathrm{p}$. 645-662. USA: Elsevier. https://doi.org/10.1016/ B978-0-12-374628-3.00040-2

Li, H., Tsao, R. and Deng, Z. (2012). Factors affecting the antioxidant potential and health benefits of plant foods. Canadian Journal of Plant Science, 92(6), 1101-1111. https://doi.org/10.4141/cjps2011-239

Litz, R.E. (2009). The Mango. $2^{\text {nd }}$ ed., p. 680. Cambridge, USA: CAB International.

Ma, X., Wu, H., Liu, L., Yao, Q., Wang, S., Zhan, R., Xing, S. and Zhou, Y. (2011). Polyphenolic compounds and antioxidant properties in mango fruits. Scientia Horticulturae, 129(1), 102-107. https://doi.org/10.1016/j.scienta.2011.03.015

Masibo, M. and He, Q. (2008). Major mango polyphenols and their potential significance to human health. Comprehensive Reviews in Food Science and Food Safety, 7(4), 309-319. https:// doi.org/10.1111/j.1541-4337.2008.00047.x

Molyneux, R.J., Lee, S.T., Gardner, D.R., Panter, K.E. and James, L.F. (2007). Phytochemicals: the good, the bad and the ugly? Phytochemistry, 68(22-24), 2973-2985.

https://doi.org/10.1016/

j.phytochem.2007.09.004

Ortega, V.G., Ramirez, J.A., Velazques, G., Tovar, B., Mata, M. and Montalvo, E. (2013). Effect of high hydrostatic pressure on antioxidant content of 'ataulfo' mango during postharvest maturation. Food Science and Technology (Campinas), 33(3), 561568. https://doi.org/10.1590/S010120612013005000062

Panche, A.N., Diwan, A.D. and Chandra, S.R. (2016). Flavonoids: an overview. Journal of Nutritional Science, 5(47), 1-15. https://doi.org/10.1017/ jns.2016.41

Parvez, G.M.M. (2016). Pharmacological Activities of Mango (Mangifera Indica): A Review. Journal of Pharmacognosy and Phytochemistry, 5(3), 01-07.

Ribeiro, S.M.R., Barbosa, L.C.A., Queiroz, J.H., Knodler, M. and Schieber, A. (2008). Phenolic compounds and antioxidant capacity of Brazilian mango (Mangifera indica L.) varieties. Food Chemistry, 110(3), 620-626. https://doi.org/10.1016/ j.foodchem.2008.02.067

Schieber, A., Bernardini, N. and Carle, R. (2003). Identification of flavonol and xanthone glycosides from mango (Mangifera indica L. cv. "Tommy Atkins") peels by High-Performance Liquid Chromatography-Electrospray Ionization Mass Spectrometry. Journal of Agricultural and Food Chemistry, 51, 5006-5011. https://doi.org/10.1021/ jf030218f

Schieber, A., Stinzing, F.C. and Carle, R. (2001). Byproducts of plant food processing as a source of functional compounds: Recent developments. Trends in Food Science and Technology, 12(11), 401-413. https://doi.org/10.1016/S0924-2244(02)00012-2

Schieber, A., Ullrich, W. and Carle, R. (2000). Characterization of polyphenols in mango puree concentrate by HPLC with diode array and mass spectrometric detection. Innovative Food Science and Emerging Technologies, 1(2), 161-166. https:// doi.org/10.1016/S1466-8564(00)00015-1 
Sharaf, A.M., Elfaham, S.Y., Mohsen, M.S. and Amhed, A.Z. (2016). Utilization of mango peels as a source of polyphenolic antioxidants. Current Science International, 5(4), 2077-4435.

Stark, K.F., Couto, V. and Gereffi, G. (2017). The Philippines in the Mango Global Value Chain. Center on Globalization, Governance, and Competitiveness. Retrieved from Duke CGGC Website: http://industry.gov.ph/wp-content/ uploads/2017/08/The-Philippines-in-the-MangoGlobal-Value-Chain.pdf

STATISTA. (2018). Mango production worldwide from 2000 to 2017 (in million metric tons). Retrieved on 28 October 2018 from https://www.statista.com/ statistics/577951/world-mango-production/

Varakumar, S., Kumar, Y.S. and Reddy, O.V. (2011). Carotenoid composition of mango (Mangifera indica L.) wine and its antioxidant activity. Journal of Food Biochemistry, 35(5), 1538-1547. https:// doi.org/10.1111/j.1745-4514.2010.00476.x

Velioglu, Y.S., Mazza, G., Gao, L. and Oomah, D. (1998). Antioxidant activity and total phenolics in selected fruits, vegetables, and grain products. Journal of Agricultural Food Chemistry, 46(10), 4113-4117. https://doi.org/10.1021/jf9801973

Zhishen, J., Mengcheng, T. and Jianming, W. (1999). The determination of flavonoid contents in mulberry and their scavenging effects on superoxide radicals. Food Chemistry, 64(4), 555-559. https:// doi.org/10.1016/S0308-8146(98)00102-2 